\title{
A ESTRUTURA FUNDIÁRIA E CAFEEIRA DE DOIS MUNICÍPIOS DO OESTE PAULISTA: CAMPINAS E RIBEIRÃO PRETO NO INÍCIO DO SÉCULO XX*
}

\author{
Renato Leite Marcondes \\ Faculdade de Economia, Administração e Contabilidade de \\ Ribeirão Preto, Universidade de São Paulo
}

\begin{abstract}
Resumo
A cafeicultura foi muito importante para o desenvolvimento do Estado de São Paulo. A expansão do café ao longo do território paulista ocorreu em diferentes períodos e em diferentes dimensões que marcaram a estrutura produtiva das regiões. Desde pequenos até grandes produtores participaram da faina cafeeira. Analisamos a estrutura fundiária e de cultivo do café de dois dos principais municípios cafeeiros no início do século XX: Campinas e Ribeirão Preto. Mesmo produzindo grandes volumes de café e situados no oeste paulista, verificamos, com certas diferenças, a importância dos pequenos e grandes cafeicultores em ambos os municípios. Por fim, notamos distinções importantes da concentração da produção, das terras e dos cafezais.
\end{abstract}

Pallavras-chave

Posse de cafezais $\bullet$ propriedade de terras • Ribeirão Preto e Campinas.

Contato:

Av. dos Bandeirantes, 3900 - bloco C - sala 73

Campus USP/FEA-RP

14040-905 - Ribeirão Preto - SP

E-mail:rlmarcon@usp.br 


\title{
COFFEE AND LAND OWNERSHIP'S IN TWO MUNICIPALITIES OF WEST OF SÃO PAULO: CAMPINAS E RIBEIRÃO PRETO IN THE EARLY TWENTIETH CENTURY
}

\author{
Renato Leite Marcondes \\ Faculdade de Economia, Administração e \\ Contabilidade de Ribeirão Preto, Universidade de São Paulo
}

\begin{abstract}
The coffee was very important for the development of the State of São Paulo. The growth of coffee in the area occurred in different periods, which marked the productive structure of regions. From small to large producers participated in the cultivation of coffee. We analyze the structure of land ownership and cultivation of coffee in two of major municipalities coffee's in the early twentieth century: Campinas and Ribeirão Preto. Even producing large volumes of coffee and situated in the west of São Paulo, we found, with certain differences, the importance of small and big farmers in both municipalities. Finally, we note important distinctions concentration of production, land and coffee plantations.
\end{abstract}

\section{Keywords}

Coffee holdings $\bullet$ landholdings $\bullet$ Ribeirão Preto $\bullet$ Campinas.

\section{Contact:}

Av. dos Bandeirantes, 3900 - bloco C - sala 73

Campus USP/FEA-RP

14040-905 - Ribeirão Preto - SP

E-mail: rlmarcon@usp.br 
O paulista de velha estirpe acompanha orgulhosamente a marcha para oeste. Comprazia-se em contar como seu avô abandonara a fazenda do vale do Paraíba pela região de Campinas; em seguida seu pai abrira uma plantação na zona de Ribeirão Preto; e ele, por sua vez, continuava a desbravar a floresta na Alta Paulista ou norte do Paraná. Realiza o filho do imigrante, em uma geração, o que a família paulista fizera em três etapas.

Monbeig, 1984, p. 123.

O Estado de São Paulo foi o maior produtor de café do país desde o final do século XIX até o término da primeira metade do XX. Depois de ocupar os morros de meia laranja do vale do Paraíba a partir do final do século XVIII, o cafeeiro atingiu o oeste paulista. ${ }^{1}$ Esta área tornou-se a principal região produtora no período áureo da preciosa rubiácea no Estado, apresentando melhores condições de produção tanto geográficas quanto técnicas de cultivo e beneficiamento. Vários estudos contaram esta trajetória do café em São Paulo, dos quais se destacaram os clássicos de Sergio Milliet (1939), Pierre Monbeig (originalmente 1952, 1984) e José Francisco de Camargo (1952). Estes autores demonstraram o ritmo do avanço cafeeiro no oeste, imprimindo uma marcha pioneira de ocupação de um vasto sertão ainda pouco povoado. O roteiro do café ocupou, em distintos momentos e profusões, a maior parte do Estado de São Paulo, à exceção da região da capital, do vale do Ribeira e do litoral sul. Todavia, poucos estudos analisam a estrutura fundiária e cafeeira dos municípios paulistas daquela época.

A marcha do café no Estado de São Paulo apresentou grande heterogeneidade entre os municípios produtores em termos do número de pés de café ou de produção. Num momento, municípios em diferentes estágios do ciclo produtivo se encontravam em atividade, desde o início, auge e declínio. Contudo, tal diferenciação não se reduziu a esta explicação. Outros elementos devem ser elencados para justificar distinções de produção, como solo, clima, relevo, mas também

\footnotetext{
1 Taunay (1939) afirmou que o início do cultivo do café em São Paulo ocorreu, ao final do século XVIII, por meio do vale do Paraíba em paralelo ao seu cultivo no litoral norte da capitania, particularmente Ubatuba e vila Bela. As listas nominativas de habitantes demonstram a existência de produção e exportação de café nas vilas do vale e do litoral norte fronteiriças ao Rio de Janeiro nessa época. Por fim, as informações dos carregamentos dos navios chegados em Lisboa revelam que o café já era embarcado em Santos em junho de 1790. O total enviado por esta embarcação foi de apenas 19 arrobas, totalizando $97 \$ 280$ réis. Nos anos seguintes, os embarques tornaram-se regulares em quantidades crescentes. Deste modo, o cultivo em pequena escala já era bastante comum no território paulista desde o final do século XVIII.
} 
fatores demográficos, históricos e econômicos, como a forma do povoamento, condições prévias e atração de investimentos. Tais elementos condicionam-se mutuamente. Assim, a grande diversidade de municípios produtores foi uma marca da marcha do café. Para facilitar o entendimento desta diversidade de situações, neste artigo, consideramos as estruturas produtivas de dois dos mais importantes centros na faina do café: Campinas e Ribeirão Preto. Dois municípios de destacada produção deveriam estruturar sua atividade cafeeira em um conjunto bastante assemelhado de produtores.

A cafeicultura revelou uma correlação elevada com os movimentos populacionais quando analisamos unidades territoriais comparáveis. A expansão do café necessitou de braços para a lavoura, revelando uma dinâmica muito próxima entre a produção e a mão-de-obra. Trabalhadores livres e escravos participaram da faina cafeeira. Os não-proprietários de cativos começaram o seu cultivo ainda no século XVIII. Posteriormente, os escravistas ganharam destaque. Grandes levas de trabalhadores escravos labutaram nos cafezais. Na segunda metade do século, o declínio da disponibilidade relativa de cativos conduziu a uma tendência de retração do emprego desses braços nas lavouras. A entrada de grandes massas de imigrantes estrangeiros na década de 1880 acelerou a transição para o trabalho livre por meio do colonato, especialmente no oeste paulista. ${ }^{2}$

O momento crucial de mudança do panorama da região ocorreu entre 1870 e 1890 em virtude do avanço ferroviário e da chegada das levas de imigrantes estrangeiros. Segundo Monbeig: "Trata-se ainda da continuação do movimento iniciado nas terras montanhosas do Estado do Rio de Janeiro. Mas o quadro físico não era o mesmo e, o que é mais significativo, tendo as instituições sociais evoluído, as marcas deixadas pelo homem na paisagem haviam mudado" (1984, p. 177).

Segundo Caio Prado Júnior em artigo publicado originalmente em 1935 e dados estimados para 1932-33, a estrutura fundiária paulista mostrava, nesse momento, uma grande concentração: "Para o conjunto do Estado, predomina também a grande propriedade [acima de 100 alqueires / RLM], com mais de $50 \%$ da área agrícola total. (...) Salvo na faixa de território que borda o litoral, a pequena propriedade tem um papel insignificante; e mesmo nesta parte do Estado, só na zona da capital ela é realmente importante" (1945, p. 694). Para o autor, a causa desta condição decorreu do sistema de distribuição de terras adotada pela coroa portuguesa no processo de colonização, especialmente a concessão de sesmarias. A doação de grandes áreas, não apenas em São Paulo bem como em

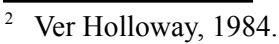


todo o Brasil, foi a razão principal desta concentração. ${ }^{3}$ A cafeicultura continuou um processo mais antigo de ocupação do território.

Ainda de acordo com Caio Prado: “A pequena propriedade, pelo contrário, tem uma história mais recente. Constituiu-se depois da grande, e em regra às suas expensas. Primeiro vem a grande propriedade; depois, retalhando-se esta, surge a média e a pequena" (1945, p. 696). Segundo ele, a formação destas posses menores pode ser condicionada por cinco grupos de fatores: necessidade de braços para as fazendas, decomposição da fazenda, influência dos centros urbanos, a colonização oficial e a particular. Deste modo, procuramos, nesse artigo, avançar no entendimento da estrutura fundiária rural e cafeeira de dois grandes centros cafeicultores no início do século XX, baseados no censo agrícola de 1904-05 e dados da posse de cafezais até a década de 1930.

Nessa grande área do oeste paulista, Campinas e Ribeirão Preto destacaram-se em momentos distintos na produção de café. De início apresentaremos o evolver mais geral da produção e da população dos dois centros. A invasão cafeeira alcançou os dois municípios em momentos distintos, ocorrendo, no primeiro caso. já no quarto inicial do século XIX marcado profundamente pela mão-de-obra cativa e a disponibilidade da oferta africana. No segundo, o cafeeiro chegou à década de 1870 quando a escravidão já mostrava sinais de declínio. Posteriormente, comparamos os dois num momento para o qual possuímos maiores informações, principalmente acerca de suas estruturas fundiárias rurais e, posteriormente, da distribuição dos cafeeiros. Por fim, tentamos relacionar similitudes e distinções entre dois grandes municípios cafeeiros.

\section{Produção em Campinas e Ribeirão Preto}

Campinas atingiu grande pujança ainda na primeira metade do século XIX por meio da cana-de-açúcar e um rápido afluxo demográfico. De acordo com Daniel

\footnotetext{
O sistema de sesmarias encerrou-se em 1822, quando ainda não se ocupara a maior parte do atual Estado de São Paulo. Posteriormente, vigorou apenas a posse "mansa e pacífica", desde que cultivada, de novas áreas, legitimada pela lei de terras de 1850. Contudo, as posses continuaram a ser reconhecidas, dependendo da região, até o início do século XX, bem como havia também doações de terras por parte do Estado, em geral a colonos (ver Silva, 1996, e Nozoe, 2006). De outro lado, a compra tornou-se cada vez mais comum no século XIX como forma de aquisição de propriedade, tornando uma das principais formas declaradas no registro paroquial de 1854, mesmo no oeste paulista (ver Bacellar, 1999, p. 91-116 e 1991). Assim, outras visões são importantes para complementar a discussão da formação das grandes propriedades. Uma ilustração para o caso de Ribeirão Preto consiste no estudo de Ernesta Zamboni (2001) que analisou o processo de compra e venda de imóveis e observou a possibilidade de formação do latifúndio por meio de várias aquisições de áreas de tamanhos diversos.
} 
Pedro Muller, o distrito campineiro detinha 93 engenhos em 1836 e tão-somente nove fazendas de café. De modo semelhante, a produção de açúcar totalizava 158 mil arrobas, enquanto a de café apenas oito mil. O dinamismo econômico apoiavase também no demográfico. A população já se mostrava expressiva, somando pouco mais de seis mil habitantes. A importância dos escravos entre seus moradores já se destacava, em virtude de totalizarem quase quatro mil pessoas. Apesar de não constituir o maior contingente cativo da província de São Paulo naquele momento, Campinas apresentava a maior proporção de escravos na população: 58,6\%. ${ }^{4}$

Em 1854, Campinas centralizou sua produção no café que chegou a 336 mil arrobas em 177 fazendas. Em menos de duas décadas, a colheita da preciosa rubiácea multiplicou-se em mais de quarenta vezes. Por outro lado, a produção de açúcar reduziu-se a 62 mil arrobas em 44 fazendas, menos da metade da safra de 1836. No seu mútuo condicionamento, a população cresceu, ou melhor, mais do que dobrou, para pouco mais de catorze mil pessoas, dos quais cerca de oito mil escravos. A proporção deste último contingente em relação ao total dos habitantes manteve-se num patamar relativamente próximo: 57,4\%. Destarte, o crescimento cafeeiro lançou mão de uma proporção de trabalhadores escravos assemelhada à da cultura canavieira.

Segundo Auguste Zaluar, o café expandiu-se a 700 mil arrobas em 189 fazendas no início da década de 1860 (1975, p. 136). A colheita de açúcar estagnou-se no patamar anterior. No primeiro censo do Império, a população campineira alcançou cerca de trinta e um mil habitantes, novamente mais do que dobrou em menos de duas décadas mantendo um dinamismo muito vigoroso. ${ }^{5}$ Embora o número de escravos do município tenha crescido a quase catorze mil, o fim do tráfico dificultou a manutenção da proporção de escravos entre os moradores, diminuindo para 43,6\% em 1874. Todavia, ainda era mais do que o dobro da média da província. De acordo com as informações disponibilizadas por Laerne, a população escrava ainda cresceu até o início da década de 1880, atingindo seu apogeu em 1883, quando totalizou 15.665 pessoas (1885, p. 115). Tal contingente era o maior da província e um dos maiores de toda a região cafeeira do Sudeste, inferior apenas aos de alguns municípios do vale do Paraíba fluminense (Vassouras, Valença, Cantagalo e São Fidelis) e mineiro (Juiz de Fora e Leopoldina).

\footnotetext{
4 Somente dois outros municípios paulistas detinham mais escravos do que livres nesse ano: Bananal, grande município cafeeiro do vale do Paraíba, e Capivari, produtor de açúcar próximo a Itu.

5 Segundo Semeghini (1991, p. 49), Campinas contou, nesse período de 1854 a 1874, com um forte afluxo imigratório principalmente de pessoas livres, respondendo por mais da metade do aumento demográfico entre esses anos.
} 
Em 1886, a safra de café de Campinas foi a maior da província, atingindo até 1,5 milhão de arrobas. Ao que tudo indica, a partir deste patamar superior a um milhão de arrobas, a produção de café permaneceu com oscilações habituais das colheitas até a grande geada de 1918, como pode ser observado no gráfico 1. Após este declínio, a produção recuperou-se e manteve-se ao redor de um milhão de arrobas até 1930.

Os impostos municipais sobre o café começaram a ser cobrados em São Paulo

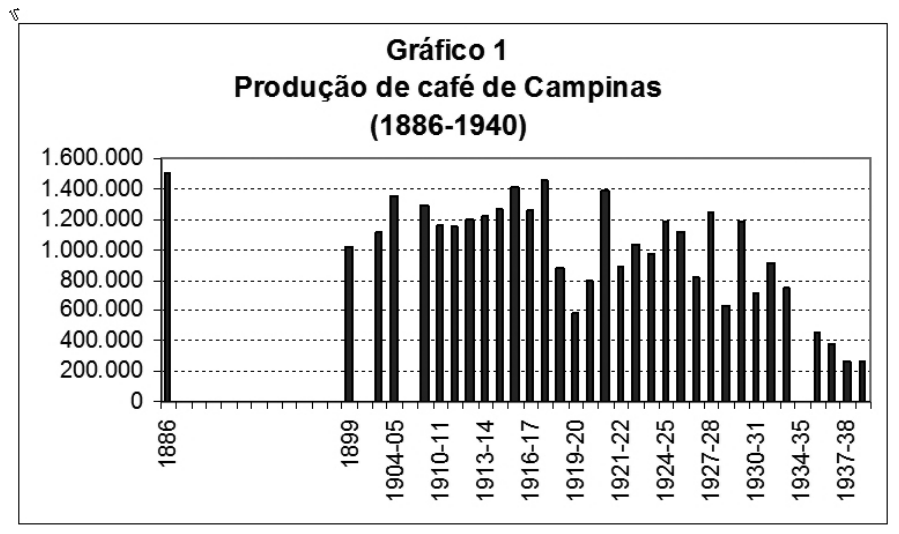

no Império, de início sobre a produção, mas, posteriormente, sobre o tamanho dos cafezais. ${ }^{6}$ No caso de Campinas, o primeiro registro mais completo refere-se a 1899 , no qual foram colhidas pouco mais de um milhão de arrobas. Este registro permite conhecer o número total de produtores que chegou a 274 nesse momento. A produção média foi inferior a 4 mil arrobas por cafeicultor. A variação entre os volumes das colheitas entre os produtores revelou-se expressiva, desde os menores com apenas 20 arrobas até os maiores com 20 mil arrobas. Pouco mais de quatro décimos deles produziram até mil arrobas, porém responderam por apenas $3,7 \%$ da produção do município. Por outro lado, os cafeicultores que colheram mais de dez mil arrobas totalizaram menos de um décimo do total $(8,8 \%)$ e perfizeram quase quatro décimos da colheita desse ano (38,7\%). Estas evidências demonstram a heterogeneidade dos cafeicultores em termos do porte de colheita, compreendendo desde pequenos até grandes produtores ainda no século XIX.

\footnotetext{
${ }^{6}$ AAssembleia Legislativa do Estado autorizou a Câmara de Ubatuba a cobrar um imposto sobre a produção de café do município em 1852 para ser aplicada nas obras da matriz. Posteriormente, várias vilas também passaram a cobrar tal tributo, como Campinas em 1854. No período republicano, a Lei estadual $n^{\circ} 16$, de 13 de novembro de 1891, autorizou, entre outros impostos, os municípios a cobrarem o imposto de até 40 réis por arroba de café produzida, independente de exportada ou não.
} 
A população total continuou a aumentar, chegando a mais de quarenta mil pessoas em 1886. Contudo, o número de cativos reduziu-se a pouco menos de dez mil matriculados até 1887, como ocorrido no restante do país. A proporção deles na população total retraiu-se a $24,2 \%$, mas representava quase o triplo da média da província. A entrada de imigrantes estrangeiros acentuou-se ao final da década de 1880 , atingindo $20,8 \%$ da população em 1890 . Nos anos seguintes, as entradas não foram tão expressivas, mas se manteve o patamar no censo de $1920(20,3 \%)$.

Na década de 1930, a redução das safras mostrou-se acelerada e cresceu a diversificação agrícola e econômica, como salienta Milliet:

Campinas ainda é o primeiro centro produtor [da região central], tanto do café como do algodão e do açúcar. Sua situação privilegiada, a excelência de suas terras, vão mantê-la num regime de estabilidade que a própria crise e a abertura do sertão não conseguirão abalar. 1935 alcança-a em pleno progresso, com uma população de 133.000 habitantes, nova capital, "princesa do oeste" reinando sobre o vasto hinterland da Mogiana, Paulista e Araraquarense. A pequena propriedade se instala, com a emigração dos latifúndios para as terras virgens, e novas culturas lhe vêm aumentar a riqueza (Milliet, 1939, p. 48).

Como se tratou de uma região produtora desde a primeira metade do século XIX, a produtividade dos cafezais não se mostrou tão elevada quanto nas novas áreas de cultivo (como veremos adiante Ribeirão Preto), mantendo-se entre 40 e 50 arrobas do início do século XX até a geada, conforme o gráfico 2. Posteriormente, retornou a um patamar assemelhado, reduzindo mais pronunciadamente apenas na década de 1930. Deste modo, o ciclo cafeeiro de Campinas revelou-se, comparativamente ao próximo caso analisado, bastante longo e estável desde a primeira metade do século XIX até a década de 1930, lançando mão de população cativa e de imigrantes estrangeiros. De acordo com os dados organizados por Testa referentes ao meado da década de 1930: "Campinas possui os mais velhos cafeeiros do Estado, cuja idade varia, em geral, de 55 a 80 anos" (1938, p. 94). Por outro lado, reforçou-se a tendência de polo regional e principal eixo ferroviário para a ligação com o norte e o oeste do Estado, favorecendo o comércio e as atividades urbano-industriais (ver Semeghini, 1991).

O café alcançou a região de Ribeirão Preto na década de 1870, favorecido pelo início da expansão ferroviária no oeste paulista e atraído por condições geográficas propícias, como as afamadas terras roxas, topografia e clima. A difusão do cafeeiro no município beneficiou-se dos investimentos das famílias Pereira Barreto, Prado e Dumont e da divulgação dos seus atrativos para o cultivo da preciosa rubiácea, valorizando as suas terras (ver Caldeira, 2003). De início, os primeiros cafezais ainda eram relativamente pequenos, compreendendo poucos 


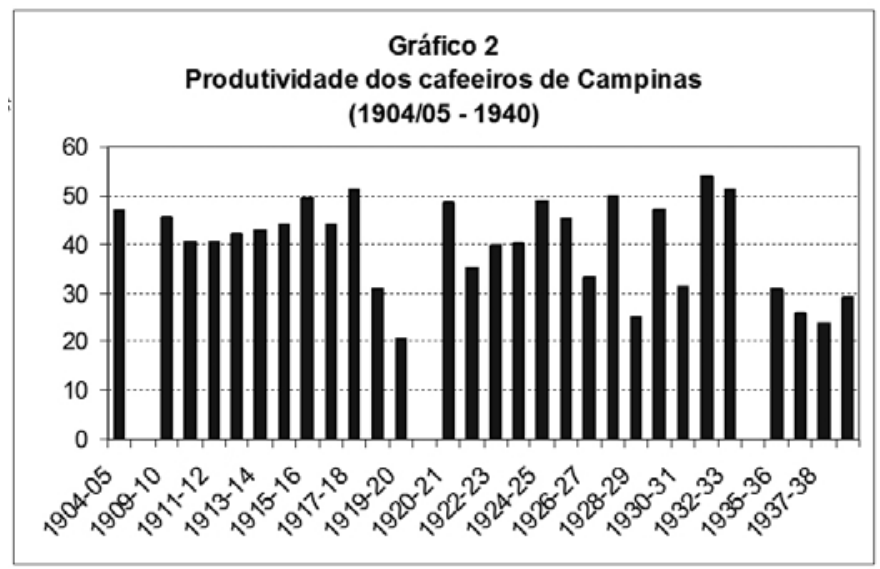

milhares de cafeeiros e com apoio da mão-de-obra cativa. Entre 1874 e 1883, a população escrava do município cresceu significativamente, passando de 857 para 1.386, segundo Laerne (1885, p. 116). ${ }^{7}$ Este crescimento foi um dos maiores da província no período, contrariando a redução desta população ocorrida no país.

No segundo lustro da década de 1880, o plantio acelerou-se, atingindo volumes mais expressivos e ganhando escala extraordinária, favorecido pelo ingresso crescente de imigrantes estrangeiros. Os estrangeiros perfizeram 7,3\% da população em 1886 e cresceram para 10,7\% em 1890, ainda inferior à proporção de Campinas. Deste modo, a colheita da preciosa rubiácea em Ribeirão Preto cresceu expressivamente ao final do século XIX.

Os primeiros informes mais completos da produção, provavelmente de origem tributária e referentes a 1890, apontaram a existência de pouco menos de uma centena de cafeicultores. A produção somou pouco mais de duzentas mil arrobas, conforme o gráfico 3, pois a maioria desses cafeeiros ainda era nova. Entre eles, destacava-se Henrique Dumont, produzindo 50 mil arrobas da preciosa rubiácea, quase um quarto do total. ${ }^{8} \mathrm{O}$ maior cafeicultor do município, nesse momento, superava os maiores e tradicionais produtores campineiros ao final do século XIX.

7 A razão de sexo desta população alcançou 195 em 1874, demonstrando a escolha por homens mais aptos para o trabalho agrícola. Em Campinas, a razão mostrava-se ligeiramente menor: 181 .

8 Neste momento, Ribeirão Preto compreendia Cravinhos e Sertãozinho, porém não incluímos as informações das duas cidades em nosso estudo. A primeira já se destacava com uma razoável produção de quase quarenta mil arrobas em onze unidades produtivas e a segunda de pouco menos de cinco mil em dez propriedades. A fonte dessas informações é a Ata n ${ }^{\circ} 10$, depositada no Arquivo Municipal de Ribeirão Preto. Não há indicação de ano desta fonte; estimamos que são, possivelmente, de 1890, em função das pessoas presentes e dos documentos anteriores e posteriores. 
Isto salienta o porte alcançado pela cafeicultura em Ribeirão Preto, derivado dos investimentos elevados realizados por abastados fazendeiros. ${ }^{9}$

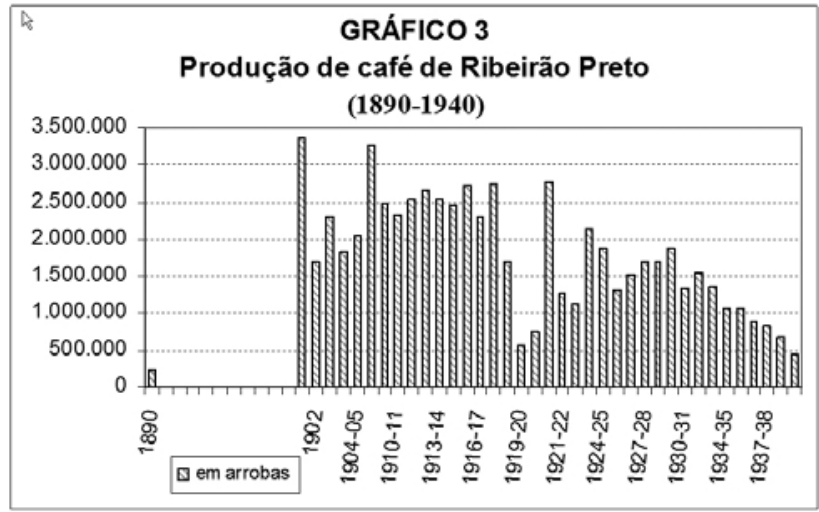

No início do século XX, o número de cafeicultores mais do que dobrou para cerca de duas centenas e a produção atingiu mais de dois milhões de arrobas. Nesse momento, dos quase trinta milhões de pés existentes em Ribeirão mais de quatro quintos tinham seis anos ou mais de idade, apontando para grande expansão cafeeira entre 1885 e 1896 quando os preços também se mostravam favoráveis. Posteriormente, não ocorreu mais a expansão significativa do número de cafeeiros, tão-somente a renovação dos pés mais velhos ou deteriorados.

Nesse período, o café suplantava amplamente as demais atividades agrícolas. Nas duas primeiras décadas do século XX, a colheita de café em Ribeirão Preto superou a dos demais municípios do Estado. O crescimento da população estrangeira auxiliou tal expansão, a qual atingiu, em 1920, quase um terço do total $(31,6 \%)$, muito superior à de Campinas. Assim, corrobora-se a importância desse contingente para a expansão cafeeira do município, especialmente anterior a Primeira Grande Guerra.

A produção permaneceu, na década de 1900 e até 1916-17, num patamar superior a dois milhões de arrobas. Nesse último ano, quatro produtores detinham

9 De acordo com as escrituras de compra e venda de imóveis, verificamos que Henrique Dumont adquiriu onze propriedades rurais de variados tamanhos entre 1880 e 1887 e, posteriormente, a Companhia Dumont realizou nove aquisições entre 1890 e 1895. Por fim, há uma aquisição isolada em 1908. Apesar da companhia como um todo ter sido vendida na década de 1890, Dumont vendeu tãosomente uma casa urbana nas escrituras. Assim, este caso reforça o processo de formação de grande propriedade por meio de várias compras. A trajetória de Francisco Schmidt revelou-se semelhante à de Dumont, adquirindo 28 propriedades por compra e apenas duas vendas em cerca de uma década com o apoio financeiro da casa exportadora Theodor Wille (cf. Caldeira \& Marcondes, 2003, p.130). 
mais de um milhão de pés: coronel Francisco Schmidt, Companhia Agrícola Fazenda Dumont, Companhia Guatapará e dona Francisca Silveira do Val. Destarte, no início do século XX, Ribeirão Preto consistiu no maior produtor de café do Estado de São Paulo e, provavelmente, do país.

A geada de 1918 reduziu significativamente a produção e a produtividade (ver gráfico 4). A primeira atingiu, em 1919-20, apenas 560 mil arrobas. A segunda mantinha-se pouco inferior a 90 arrobas por mil pés até a geada, diminuindo para cerca de 60 na década de 1920 e chegando ao final da década de 1930 a pouco mais de 30 arrobas. O censo de 1920 também mostrou uma redução do número de estabelecimentos plantadores de café para 141, talvez ainda reflexo da geada de dois anos antes. Ribeirão Preto já não era mais o principal produtor de café do Estado. Deste modo, a produção total alcançou tão-somente 741.080 arrobas no recenseamento. A produção recuperouse nos anos seguintes, mas não nos mesmos patamares de antes. Assim, a crise de 1929 tão-somente acentuou uma retração iniciada anteriormente.

Além da diminuição das safras de Ribeirão Preto, a expansão cafeeira mais para o oeste e o sul provocou uma redução da participação do município no total colhido no Estado. Esta parcela chegou a 6,0\% em 1911/12, mas, em 1925/26, já foi de 3,3\%. No final da década seguinte, a produção de café de Ribeirão representou tão-somente 1,4\% do total do Estado de São Paulo na safra de 1937-38. Assim, consolidou-se a retração da importância do município na cafeicultura paulista, revelando um ciclo de produção mais curto e intenso do que o de Campinas. ${ }^{10}$ No município, cresceram as colheitas de outras culturas, como o algodão e a cana-de-açúcar, bem como algumas atividades urbanas.

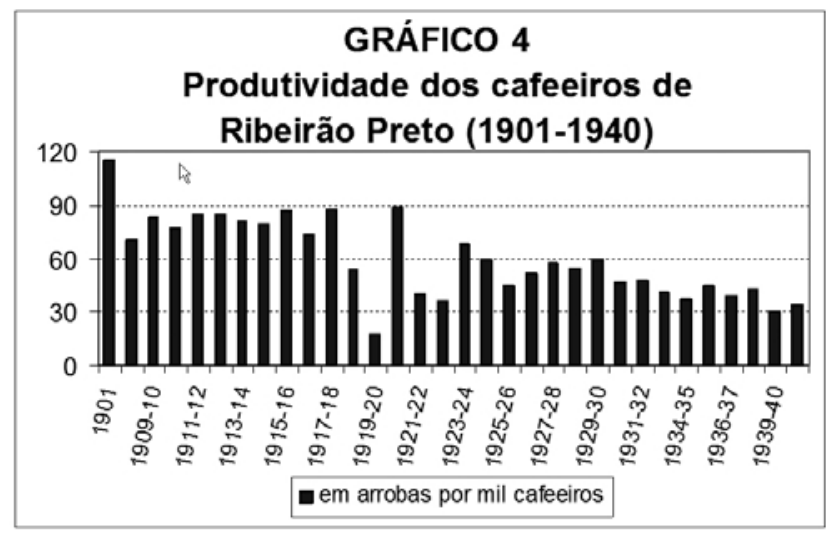

${ }^{10}$ A idade dos cafeeiros oscilou entre 30 e 55 anos, segundo as informações de 1935 (cf. Testa, 1938, p. 387). 


\section{Estrutura fundiária em 1904-05}

A partir do levantamento da Secretaria da Agricultura de 1904-05, podemos comparar os dois municípios de modo bastante detalhado. Nesse momento, o ciclo cafeeiro apresentou-se em distintas fases nos dois municípios, mostrando ainda o apogeu de Campinas e o início do vigor em Ribeirão Preto. Todavia, as produções atingiram, nesse momento, patamares elevados nos dois municípios, acima de um milhão de arrobas.

Tal comparação mostrou-se interessante em função das condições da produção nos dois municípios, como fornecida na tabela 1. Apesar de Campinas possuir uma área total pouco maior, o território ocupado pela cultura do café revelou-se bastante assemelhado, com ligeira superioridade para Ribeirão Preto. Isto se refletiu num estoque de cafezais também muito semelhante nos dois municípios. Os cafezais cobriram cerca de $30,2 \%$ da área das propriedades deste último município contra $24,8 \%$ no outro. Todavia, o volume de produção bastante distinto, alcançando em Campinas cerca de dois terços do de Ribeirão. Destarte, a produtividade também se mantinha nesta proporção, salientando os momentos distintos do ciclo.

\section{Tabela 1 - Características da produção em Campinas e Ribeirão Preto em 1904-05}

\begin{tabular}{|l|r|r|}
\hline \multicolumn{1}{|c|}{ Características } & Campinas & Ribeirão Preto \\
\hline $\mathrm{N}^{\text {o de propriedades }}$ & 641 & 261 \\
\hline $\mathrm{N}^{\text {o de proprietários }}$ & 614 & 240 \\
\hline Área total em alqueires & 57.866 & 50.298 \\
\hline Valor da produção em contos & 7.072 & 8.251 \\
\hline $\mathrm{N}^{\text {o de trabalhadores }}$ & 16.953 & 21.550 \\
\hline $\mathrm{N}^{\text {o de cafeicultores* }}$ & 294 & 233 \\
\hline Área de café em alqueires & 14.371 & 15.205 \\
\hline Milhares de pés de café & 28.781 & 29.094 \\
\hline Produção de café em arrobas & 1.354 .160 & 2.059 .936 \\
\hline Produtividade: arrobas por mil pés & 47,1 & 70,9 \\
\hline * Tomamos como referência de cafeicultor a existência de terras com o plantio de café. \\
\hline
\end{tabular}

O valor da produção total não se mostrou tão distinto entre os dois municípios quanto o da cafeeira, diferindo ao redor de um sexto do total. Além da maior proporção da área ocupada, o café foi mais importante para a receita da produção de Ribeirão do que em Campinas. Deste modo, a criação de animais e outras culturas foi mais importante neste último município, como algodão, milho, aguardente e açúcar, ajudando a reduzir a diferença do valor total produzido. 
Mesmo dois municípios com áreas, cafezais e produções assemelhados mantinham uma grande diferença em termos do número de propriedades e de proprietários. Enquanto em Campinas existiam mais de seis centenas para as duas categorias, verificamos em Ribeirão cerca de duas centenas e meia. Os cafeicultores apresentaram importância relativa maior neste último, representando a quase totalidade dos proprietários. No primeiro, tal proporção não chegou à metade, totalizando quase três centenas. Outrossim, a maior parte dos proprietários de Campinas não detinha terras com plantio de café, ao contrário de Ribeirão Preto. Por fim, a ocupação mais antiga favoreceu a fragmentação das posses dos proprietários em Campinas, especialmente de não produtores de café, como pode ser observado na tabela 2 .

\section{Tabela 2 - Distribuição dos proprietários segundo faixa de tamanho em 1904-05}

\begin{tabular}{|l|r|r|r|r|}
\hline \multirow{2}{*}{ Faixas em alqueires } & \multicolumn{2}{|c|}{ Campinas } & \multicolumn{2}{c|}{ Ribeirão Preto } \\
\cline { 2 - 5 } & Número & $\mathbf{1 \%}$ & Número & $\mathbf{\%}$ \\
\hline Até 10 & 194 & 31,6 & 84 & 35,0 \\
\hline De $10-\mid 25$ & 111 & 18,1 & 46 & 19,2 \\
\hline De $25-\mid 50$ & 103 & 16,8 & 24 & 10,0 \\
\hline De $50-\mid 100$ & 74 & 12,0 & 23 & 9,6 \\
\hline De $100-\mid 250$ & 84 & 13,7 & 40 & 16,7 \\
\hline De $250-\mid 500$ & 28 & 4,5 & 4 & 1,7 \\
\hline De $500-\mid 1.000$ & 11 & 1,8 & 7 & 2,9 \\
\hline Mais de 1.000 & 9 & 1,5 & 12 & 5,0 \\
\hline Total & $\mathbf{6 1 4}$ & $\mathbf{1 0 0 , 0}$ & $\mathbf{2 4 0}$ & $\mathbf{1 0 0 , 0}$ \\
\hline
\end{tabular}

Seguindo a divisão já empregada na literatura clássica, ${ }^{11}$ os pequenos proprietários com posses de até 25 alqueires representaram quase a metade dos detentores de terras rurais em Campinas, enquanto em Ribeirão Preto perfizeram mais da metade. Tal situação inverteu-se na faixa dos médios fazendeiros de mais de 25 a até 100 alqueires, na qual a primeira detinha pouco mais de um quarto e a segunda menos de um quinto. Entre 100 e até 500 alqueires, os grandes mostraram equilíbrio das duas cidades, possuindo pouco menos de um quinto do total de proprietários. Por fim, os latifundiários mostraram-se mais presentes em Ribeirão, com 7,9\% do total; em Campinas apenas 3,3\%. Esta estrutura fundiária

${ }^{11}$ Como informa Caio Prado e Milliet, há grande arbitrariedade nestas escolhas em função do espaço e tempo de cada estudo. Utilizamos as faixas consideradas no próprio documento da época, mas à luz da divisão de pequenas, médias, grandes e latifúndios de Milliet. 
dos dois municípios demonstra a participação numérica expressiva da pequena propriedade. A maior importância do núcleo urbano de Campinas acentuou a produção de mercadorias distintas do café e a repartição das propriedades, em virtude da demanda de gêneros para o seu abastecimento.

$\mathrm{Na}$ tabela 3, fornecemos a distribuição das áreas entre os proprietários dos dois municípios. Apesar da área total não diferir significativamente, o tamanho médio das posses revelou-se muito distinto entre as duas cidades, chegando a 210 alqueires em Ribeirão e 94 em Campinas. Assim, notamos novamente uma fragmentação mais elevada das propriedades neste último município.

Apesar de constituírem uma parcela muito elevada dos detentores de terras, os menores proprietários detinham tão-somente 5,3\% das terras em Campinas e ainda menos em Ribeirão Preto: irrisórios $2,4 \%{ }^{12} \mathrm{Na}$ situação oposta, os latifundiários ribeirão-pretanos mantinham mais de três quartos das áreas agriculturáveis $(77,1 \%)$, muito superior à proporção campineira de $45,2 \% .{ }^{13}$ Este resultado aponta um elevado grau de concentração fundiária nos dois municípios, como já apontado por Caio Prado para as duas regiões na década de 1930. Deste modo, a desigualdade da posse das terras mostrou-se mais elevada na primeira do que na segunda, assumindo índices de Gini de 0,852 e 0,727 , respectivamente. ${ }^{14}$ As situações extremas em Ribeirão acentuaram a desigualdade das áreas entre os seus proprietários, especialmente da representatividade dos menores e maiores possuidores de terras.

${ }^{12}$ Em termos de produção de café, a participação dos menores possuidores de terras foi de 1,6\% em Campinas e 2,9\% em Ribeirão Preto.

${ }^{13}$ Com relação à colheita do café, os latifundiários detinham 18,3\% do total colhido em Campinas e 59,0\% em Ribeirão Preto. Os detentores das maiores propriedades fundiárias produziam uma parcela menor do que representavam em termos da área produtiva.

${ }^{14} \mathrm{O}$ índice de Gini é uma medida estatística de desigualdade e varia de 0 (quando todos possuem propriedade ou produção iguais) a 1 (quando um detém toda propriedade ou produção). Quanto maior o valor do índice maior será a concentração da propriedade da terra ou produção de café ou de cafeeiros. 
Renato Leite MARCONDES. A estrutura fundiária e cafeeira de dois municípios do Oeste paulista...

Tabela 3 - Distribuição das áreas dos proprietários segundo faixa de tamanho em 1904-05

\begin{tabular}{|l|c|c|c|c|}
\hline \multirow{2}{*}{ Faixas em alqueires } & \multicolumn{2}{|c|}{ Campinas } & \multicolumn{2}{c|}{ Ribeirão Preto } \\
\cline { 2 - 5 } & Número & $\mathbf{\%}$ & Número & \% \\
\hline Até 10 & 1.137 & 2,0 & 423 & 0,9 \\
\hline De $10-\mid 25$ & 1.910 & 3,3 & 774 & 1,5 \\
\hline De $25-50$ & 3.889 & 6,7 & 1.001 & 2,0 \\
\hline De $50-100$ & 5.694 & 9,8 & 1.674 & 3,3 \\
\hline De $100-\mid 250$ & 14.731 & 25,5 & 6.534 & 13,0 \\
\hline De $250-500$ & 9.549 & 16,5 & 1.123 & 2,2 \\
\hline De $500-\mid 1.000$ & 6.877 & 11,9 & 5.239 & 10,4 \\
\hline Mais de 1.000 & 14.081 & 24,3 & 33.528 & 66,7 \\
\hline Total & $\mathbf{5 7 . 8 6 6}$ & $\mathbf{1 0 0 , 0}$ & $\mathbf{5 0 . 2 9 9}$ & $\mathbf{1 0 0 , 0}$ \\
\hline
\end{tabular}

A presença da pequena propriedade nestes dois municípios cafeeiros demonstrou a diversidade de condições da cafeicultura. Até mesmo quando consideramos apenas os cafeicultores, o resultado permanece similar. Em Campinas, onde havia grande número de proprietários sem café, os pequenos cafeicultores representaram ligeiramente mais da metade do total $(51,4 \%)$, superando o porcentual da pequena propriedade em relação a todos os proprietários, como visto na tabela 2. Como somente sete proprietários não plantavam café em Ribeirão, o resultado foi muito próximo ao do seu conjunto. Esta dinâmica já foi apontada por Milliet para os anos 1930: "a pequena propriedade se tem desenvolvido num ritmo de fato promissor, bem mais acentuado que o das outras classes" (1939, p. 116). ${ }^{15}$ As informações do censo de 1904-05 salientam para uma presença da pequena propriedade anterior à década de 1930 .

\section{Estrutura cafeeira no início do século XX}

Além da propriedade das terras, podemos observar a distribuição da posse de cafezais pelos cafeicultores nos dois municípios ainda por meio da estatística de 1904-05. Esta variável correlacionou-se fortemente à produção. ${ }^{16}$ No referente à distribuição,

\footnotetext{
${ }^{15}$ Rogério Faleiros reafirmou, calcado nos dados de Milliet, com relação a região de Campinas: “A estrutura fundiária da região Central (...) apresentou também um notável crescimento da pequena propriedade em relação ao total regional após a crise de 29 (...)" (2007, p. 57).

${ }^{16}$ Como esperado, a correlação entre a distribuição dos cafeeiros e da produção de café foi muito elevada nesse ano para os dois municípios; ou seja, quase igual à unidade.
} 
cerca de dois terços dos quase trezentos cafeicultores de Campinas detinham até 100 mil pés de café em suas propriedades (67,1\% do total). Apesar do maior volume de produção e menor número de cafeicultores em Ribeirão, os menores detentores de cafezais representaram quase três quartos do conjunto de cafeicultores $(74,6 \%)$. Quando analisamos a participação destes pequenos cafeicultores no estoque total de cafeeiros, a importância relativa reduziu-se expressivamente, atingindo $15,5 \%$ no primeiro município e $14,1 \%$ no segundo. Se compararmos com os informes fundiários, notamos uma participação maior dos pequenos nos cafeeiros do que nas terras, apontando uma menor concentração em relação aos pés de café. Mesmo detendo pouco menos de um sexto dos cafezais, as pessoas de posses menores participavam da faina cafeeira em municípios de grande produção de café.

Como já apontado, a posse dos cafeeiros e a produção mostraram-se efetivamente menos desiguais do que a das terras, alcançando índice de Gini de 0,759 para Ribeirão e de 0,631 para Campinas, como pode ser observado na tabela 4. Em outro estudo, já demonstramos que a estrutura fundiária também se revelou mais concentrada do que a da produção para os dois municípios: 0,794 para Ribeirão Preto (ver Marcondes, 2007, p. 182) e 0,646 para Campinas. ${ }^{17}$ A diferença dos Gini entre as duas cidades manteve-se na distribuição dos cafeeiros e das colheitas, bem como já apontado em relação à de terras. Apesar da distribuição da posse da terra revelar-se distinta entre as duas cidades, os pequenos proprietários com terras ou café representavam pelo menos a metade do seu conjunto tanto em Ribeirão Preto como em Campinas.

Tabela 4 - Índices de Gini de cafeeiros, produção, terras

\begin{tabular}{|l|c|c|c|c|}
\hline Município/ itens & $\mathbf{1 8 9 0 - 9 9 *}$ & $\mathbf{1 9 0 4 - 0 5}$ & $\mathbf{1 9 1 2 - 1 6 *}$ & $\mathbf{1 9 2 4}$ \\
\hline \multicolumn{5}{|c|}{ Campinas } \\
\hline Cafeeiros & - & 0,631 & 0,738 & 0,801 \\
\hline Produção & 0,607 & 0,646 & - & \\
\hline Terras & - & 0,727 & - & \\
\hline \multicolumn{5}{|c|}{ Ribeirão Preto } \\
\hline Cafeeiros & - & 0,759 & 0,812 & 0,778 \\
\hline Produção & 0,720 & 0,794 & - & - \\
\hline Terras & - & 0,852 & - & \\
\hline * Para Ribeirão Preto os anos foram 1890 e 1916 e, para Campinas, 1899 e 1912. \\
\hline
\end{tabular}

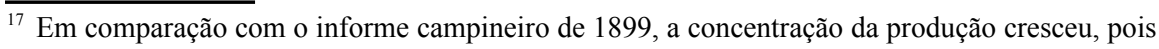
o índice de Gini era de 0,607 . 
Na ausência de informações da produção ou da estrutura fundiária posteriores a 1904-05, nesta seção exploramos outra forma de observar as distinções entre as propriedades para as décadas subsequentes, mediante o número de pés de café dos cafeicultores, como vimos para 1904-05, fortemente correlacionado com a produção. A partir do início do século, a cobrança do imposto municipal sobre o café passou a ser realizada por meio do tamanho do cafezal. Em 1912, Campinas detinha um estoque de quase 25 milhões de pés, distribuído entre 450 contribuintes. Houve um grande aumento do número de cafeicultores no município sem grande alteração dos volumes colhidos, assim se modificou expressivamente a distribuição. Dessa forma, em média, os cafeicultores mantinham cerca de 55 mil pés. Todavia, a dispersão aumentou em relação ao momento anterior de 1904-05, pois 80,3\% detinham até 100 mil pés. A presença de cafeicultores com poucos milhares de pés elevou-se nesse ano. ${ }^{18}$ Na outra extremidade da distribuição, havia duas propriedades com mais de meio milhão de cafeeiros; a da baronesa de Anhumas e de Joaquim Teixeira de Almeida Nogueira. Os poucos cafeicultores de 100 mil a 500 mil pés possuíam quase três quartos dos pés de café $(73,6 \%)$. A concentração da posse dos cafeeiros mostrou-se mais expressiva em Campinas nessa época, atingindo um Gini de 0,738, bastante superior ao mencionado anteriormente para 1904-05 (0,631).

Em Ribeirão Preto, o patamar de produção manteve-se, mas o número de contribuintes cresceu a 276 para o ano de 1916. Dessa forma, a presença dos cafeicultores com menos de cem mil pés aumentou ligeiramente a 78,3\% dos produtores, mas representavam apenas $11,6 \%$ do total de cafeeiros. A distribuição dos cafezais continuou a se revelar mais desigual do que a campineira $(0,812)$. Tais resultados salientaram a concentração da propriedade cafeeira nos dois municípios, inicialmente verificada para a produção entre o final do século XIX e 1904-05 e, a partir desse último ano até a década de 1910, por meio da posse dos cafezais. Os patamares de concentração, independente da medida, apontaram uma desigualdade superior em Ribeirão Preto com relação a Campinas desde o final do século XIX até a década de 1910.

Nas décadas de 1910 a 1930, realizou-se periodicamente um levantamento da distribuição dos cafezais entre os municípios do Estado, baseado na arrecadação do imposto sobre cafeeiros. Utilizamos as informações publicadas no boletim

\footnotetext{
${ }^{18}$ Em 1904-05, havia 82 cafeicultores que detinham menos de dez mil pés de café, dos quais apenas um com menos de mil cafeeiros. Por outro lado, em 1912, existiam 241 cafeicultores com cafezais inferiores a dez mil pés, entre os quais 33 possuíam menos de mil cafeeiros. Deste modo, podemos entender o crescimento da desigualdade e do índice de Gini entre os dois anos, pois se elevou a diferença entre os menores e maiores cafeicultores.
} 
O café da Secretaria da Agricultura. Num momento de aprofundamento das mudanças na agricultura paulista em razão da grande depressão, conseguimos avaliar o estoque de plantas disponíveis para a produção. Os cafezais de Campinas revelaram uma pequena retração no começo da década de 1920 em decorrência da geada. Todavia, somente na passagem para a década de 1930, houve uma retração mais forte dos cerca de 25 milhões da safra 1929-30 para pouco menos de quinze em 1932-33. No caso de Ribeirão, não ocorreu mudança expressiva do estoque de cafezais de mais de trinta milhões de pés na década de 1920; apenas após 1933 existiu alteração mais significativa, chegando a pouco menos de 24 milhões em 1935-36. Como o estoque de cafezais possui uma inércia elevada do período anterior e pouca flutuação, no início da década de 1930, refletiu mais as condições de produção da década anterior.

Apesar de certo declínio relativo na década de 1920, os patamares de produção ainda se mantinham elevados nos dois municípios. Contudo, o movimento de concentração caminhou em sentido oposto nas duas cidades, enquanto em Ribeirão Preto a desigualdade reduziu-se para 0,778 e, em Campinas, elevou-se para $0,801 .{ }^{19}$ Embora ainda houvesse quatro empresas/cafeicultores com mais de um milhão de pés de café na primeira cidade, Francisco Schmidt reduziu a dimensão de seus cafezais de 1916, quando era o maior produtor de pouco mais de quatro milhões, para três milhões em $1924 .{ }^{20}$ De outro lado, em Campinas, a situação alterou-se com a presença de Cristiano Osório de Oliveira e da baronesa de Anhumas, que detinham cada um quase um milhão de pés.

Se compararmos os informes de 1904-05 com os do início da década de 1930, a área cultivada com cafezais apresentou um pequeno crescimento em Ribeirão Preto, passando de 15.205 para 16.041 alqueires. Para Campinas, houve uma redução da área plantada, porém não muito expressiva, de 14.371 a 12.945 alqueires nesse último ano. Nessa época, como vimos anteriormente, o declínio da cafeicultura mostrou-se mais evidenciado, em virtude da redução significativa da produção e da produtividade nos dois casos. A redução da proporção de cafeeiros novos no total também salientou a mudança do ciclo de produção: os cafeeiros

${ }^{19}$ No caso de Campinas, em 1924, o número de contribuintes do imposto sobre cafeeiros cresceu extraordinariamente a 725 , dos quais mais de quinhentos detinham menos de dez mil pés de café. A existência de situações mais extremadas ajudou a explicar o resultado de uma concentração maior nesse momento. De outro lado, em Ribeirão Preto, depois da geada de 1918, o número de cafeicultores reduziu-se a cerca de duas centenas.

${ }^{20}$ Ao que tudo indica, o declínio da dimensão dos seus cafezais ocorreu posteriormente à geada de 1918, acentuando o ciclo de vida do cafeicultor. Ele faleceu nesse ano de 1924 e houve uma elevada fragmentação de suas fazendas. 
atingiram 12,4\% em Ribeirão Preto e tão-somente 2,6\% em Campinas, enquanto, no Estado, chegaram a um quarto do total. Como a cultura do café possui custos fixos elevados no início do cultivo, áreas menos produtivas poderiam continuar viáveis. Não obstante este declínio, o café mantinha sua importância em termos de ocupação do território dos dois municípios no início da década de 1930.

No Estado, quase a metade das propriedades detinham até cinco mil pés em 1932/33 - 41,9\% do total. Este grau de fragmentação mostrou-se muito elevado, refletindo situações bastante diversas entre os municípios, ou seja, muitos em declínio acentuado da cafeicultura: 97,3\% delas não superavam 100 mil pés. Tal padrão de distribuição das propriedades aproximou-se da distribuição em Campinas, chegando a mais de nove décimos do total. Nesta cidade, o número de propriedades com cafezais chegou a 752, mais do que o dobro daquele do início do século XX e também superior ao total em $1912 .{ }^{21}$ Desta forma, observamos um processo bastante acentuado de fragmentação das propriedades campineiras nas primeiras décadas do século XX.

O resultado de Campinas não se assemelhou ao de Ribeirão, no qual pouco mais de dois terços detinham até cem mil cafeeiros, diminuindo até sua participação em comparação ao informe de 1904-05. Em termos do número de propriedades com cafeeiros, também houve uma redução com relação ao início do século, passando de 254 a 214 nessas três décadas. A divisão das propriedades revelou-se mais expressiva na primeira cidade do que na segunda nas primeiras décadas do século XX. Deste modo, notamos, nos dois municípios, uma preponderância numérica dos pequenos cafeicultores tanto no começo desse século como na década de 1930, em todos os casos superiores a dois terços do total, contudo em contingentes diferenciados. ${ }^{22}$

$\mathrm{Na}$ condição oposta encontravam-se as propriedades com mais de meio milhão de pés de café. No Estado, somente 98 fazendas possuíam tal condição de produção, dentre estas Ribeirão Preto conservava quinze. A participação dessas últimas no total cresceu para 7,0\%, superando a parcela de $1904-05$ de $4,7 \% .{ }^{23} \mathrm{Em}$

${ }^{21}$ Em 1904-05, havia 314 propriedades com cafeeiros em Campinas.

${ }^{22}$ Vitoria Saddi (2002) demonstrou a importância das mudanças institucionais em São Paulo a partir das leis estaduais de 1895 sobre a propriedade de terras e de 1907 acerca da imigração. Finalmente, outra lei de 1921 facilitou o acesso à terra para os imigrantes estrangeiros. Assim, São Paulo tornouse um atrativo centro para o fluxo de imigrantes, recebendo não apenas imigrantes subsidiados pelo Estado. Para corroborar tal argumento, a autora mostrou a diminuição do tamanho médio das propriedades de 1904-05 para 1934, especialmente a redução do número de latifúndios (cf. 2002, p. 174).

${ }^{23}$ Em termos da concentração da posse dos pés de café houve uma redução. De acordo com o recolhimento do imposto de cafeeiros de Ribeirão Preto, o índice de Gini passou de 0,812 em 1916 para 0,747 em 1928 e 0,750 em 1934. A desconcentração ocorreu após a geada e não tanto 
Campinas, não havia mais propriedades nesta situação, ao contrário do começo do século XX quando existiam três propriedades possuindo mais de 500 mil pés. Assim, reforçamos a visão da fragmentação das propriedades campineiras de forma muito mais expressiva do que em Ribeirão Preto.

A produção média das propriedades de Campinas foi de mais quatro mil arrobas na safra 1904-05, passando a cerca de três mil e trezentas em 1917-18. No início da década de 1930, a safra média retraiu-se a tão-somente setecentas arrobas, revelando uma mudança expressiva da estrutura produtiva no período. No caso de Ribeirão Preto, a redução mostrou-se menor, passando de oito mil arrobas em 1904-05 para pouco mais de seis mil em 1932-33. Novamente, notamos uma elevada diferença do porte médio das propriedades cafeeiras dos dois municípios.

\section{Considerações finais}

Esse artigo salienta a importância da história comparada, ao analisar duas cidades de destacado papel na cafeicultura do oeste paulista que poderíamos, a princípio, pensar em condições assemelhadas de produção. Contudo, o avanço do café sobre seus territórios ocorreu em momentos diferenciados, determinando conformações fundiárias e produtivas distintas. A defasagem temporal demarcouse para Campinas, no oeste de povoamento mais antigo, e para Ribeirão Preto, no oeste de povoamento mais recente, numa expansão do café caracterizada por condições distintas, por exemplo, no referente às proporções utilizadas de trabalhadores escravos e livres, ou, também, na presença das ferrovias. No primeiro município, o ciclo produtivo cafeeiro revelou-se mais duradouro do que no segundo e precedido pela produção do açúcar.

O quadro apresentado evidenciou o desenvolvimento da cafeicultura em São Paulo de modo bastante diversificado. Até mesmo municípios de destacado papel na produção de café apresentaram estruturas fundiárias e da posse dos cafeeiros distintas. Um patamar assemelhado de colheitas superior a um milhão de arrobas de café podia ser alcançado com pouco mais de duas centenas de cafeicultores ou acima de trezentos ou quatrocentos produtores e concentrações de cafeeiros e produção entre 0,6 e 0,8 . Desse modo, a apropriação da renda cafeeira ocorria de forma bastante distinta entre os dois municípios.

O ciclo cafeeiro não se revelou homogêneo, sendo marcado pelo momento do seu roteiro. Algumas cidades foram mais abertas à presença dos pequenos e grandes cafeicultores que participaram expressivamente da faina do café nos dois

em decorrência dos efeitos da crise até o início da década de 1930. 
grandes municípios cafeeiros analisados neste artigo, extremando a distribuição das terras e dos cafeeiros. Por fim, ao longo da passagem do século XIX para o $\mathrm{XX}$, houve um aumento do número de produtores e da desigualdade da produção e dos cafezais, especialmente para Campinas. Destarte, a cafeicultura comportou situações distintas de estrutura fundiária e cafeeira nos municípios.

\section{Referências bibliográficas}

\section{Documentos}

ARQUIVO MUNICIPAL DE CAMPINAS. Lançamento do imposto sobre produção de café para o exercício de 1899.

ARQUIVO MUNICIPAL DE CAMPINAS. Lançamento do imposto sobre cafeeiros para o exercício de 1912.

ARQUIVO MUNICIPAL DE CAMPINAS. Lançamento do imposto sobre cafeeiros para o exercício de 1924.

ARQUIVO PÚBLICO E HISTÓRICO DE RIBEIRÃO PRETO. Imposto de cafeeiros e viação rural de 1916 e 1924.

DEPARTAMENTO ESTADUAL DE ESTATÍSTICA. Estatistica agrícola e zootécnica, 1939-40.

PREFEITURA MUNICIPAL DE RIBEIRÃO PRETO. Relatório de 1902 apresentado à Câmara Municipal de Ribeirão Preto pelo prefeito dr. Manoel Aureliano de Gusmão. São Paulo: Duprat, 1903.

SECRETARIA DAAGRICULTURA, COMÉRCIO E OBRAS PÚBLICAS. Estatistica agrícola e zootécnica de Campinas no ano agrícola de 1904-1905. São Paulo: Typ. Brazil/Rothschild \& Co., 1907.

SECRETARIA DAAGRICULTURA, COMÉRCIO E OBRAS PÚBLICAS. Estatistica agrícola e zootécnica de Ribeirão Preto no ano agrícola de 1904-1905. São Paulo: Typ. Brazil/Rothschild \& Co., 1907.

SECRETARIA DA AGRICULTURA, COMÉRCIO E OBRAS PÚBLICAS. O café: estatística de produção e comércio. São Paulo: Governo do Estado de São Paulo, vários anos.

SERVIÇO TÉCNICO DO CAFÉ. Relatório anual. Ribeirão Preto: Sala Ambiente, 1935 (mimeo).

\section{Publicações}

BACELLAR, Carlos Almeida Prado. Família, herança e poder em São Paulo, 17651855. Estudos Cedhal n ${ }^{\circ}$ 7. São Paulo: Cedhal, 1991.

BACELLAR, Carlos Almeida Prado. Uma rede fundiária em transição. In: BACELLAR, Carlos Almeida Prado \& BRIOSCHI, Lucila Reis. Na estrada do Anhanguera: uma visão regional da história paulista. São Paulo: Humanitas/ Ceru, 1999, p. 91-116.

CAMARGO, José Francisco. Crescimento da população no Estado de São Paulo e 
seus aspectos econômicos: ensaio sobre relações entre a demografia e a economia. São Paulo: FFLCH/USP, 1952, 3 v.

FALEIROS, Rogério Naques. Fronteiras do café: fazendeiros e "colonos" no interior paulista (1917-1937). Tese de doutorado em Economia Aplicada, IE/Unicamp, 2007.

HOLLOWAY, Thomas H. Imigrantes para o café: café e sociedade em São Paulo, 1886-1934. Rio de Janeiro: Paz \& Terra, 1984.

LAERNE, C. F. Van Delden. Brazil and Java: report on coffee-culture in America, Asia and Africa. Londres: W. H. Allen, 1885.

MARCONDES, Renato Leite. O café em Ribeirão Preto (1890-1940). História econômica \& história de empresas, v. X, 2007, p. 171-192.

MILLIET, Sérgio. Roteiro do café e outros ensaios: contribuição para o estudo da história econômica e social do Brasil. São Paulo: Departamento de Cultura, 1939.

MONBEIG, Pierre. Pioneiros e fazendeiros de São Paulo. São Paulo: Editora Hucitec/ Polis, 1984.

MÜLLER, Daniel Pedro. Ensaio d'um quadro estatístico da Província de São Paulo. São Paulo: Reedição Litteral Secção de Obras d' "O Estado de São Paulo", 1923.

NOZOE, Nelson Hideiki. Sesmarias e apossamento de terras no Brasil colônia. Revista Economia, v. 7, n. 3, set./dez. 2006, p. 587-605.

OLIVEIRA, Jorge Henrique Caldeira de. As transações imobiliárias em Ribeirão Preto de 1874 a 1899. Dissertação de mestrado em Economia, FCL/Unesp, 2003.

OLIVEIRA, Jorge Henrique Caldeira de \& MARCONDES, Renato Leite. Os negociantes de imóveis durante a expansão cafeeira em Ribeirão Preto (1874-1899). Revista Tempo - UFF, v. 15, jul. 2003, p. 111-133.

PRADO JÚNIOR, Caio. Divisão da propriedade fundiária rural no Estado de São Paulo. Boletim Geográfico, ano III, agosto 1945, nº 29.

SADDI, Vitoria. The role of coffee in the creation of institutions in Brazil: 1830-1930. Tese de doutorado em Economia, FGS/University of Southern California, 2002.

SEMEGHINI, Ulysses C. Do café à indústria: uma cidade e seu tempo. Campinas: Editora da Unicamp, 1991.

SILVA, Lígia Osório. Terras devolutas e latifúndio: efeitos da lei de 1850. Campinas: Ed. de Unicamp, 1996.

TAUNAY, Afonso de Escragnolle. Historia do café no Brasil. Rio de Janeiro: Departamento Nacional do Café (DNC), 1939, $15 \mathrm{v}$.

TESTA, J. (org.). Lavoura de São Paulo: publicação anual de estatística geral e agrícola dos municipios do Estado. São Paulo: Soc. Impressora Paulista Ltda, 1938.

ZALUAR, Augusto Emílio. Peregrinação pela província de São Paulo (1860-1861). Belo Horizonte: Itatiaia. São Paulo: Edusp, 1975.

ZAMBONI, Ernesta. Processo de formação e organização da rede fundiária da área de Ribeirão Preto (1874-1900). Estudos de História, v. 8, n. 2, 2001, p. 187-208.

Recebido: 18/11/2010 - Aprovado: 04/07/2011. 